هقاربة هنهميّة لتيسير تدريس الأصوات الملقية للنّاطقين بغير

$$
\text { المربية }
$$

The English title as follows: A methodical approach to facilitate the teaching of the Throatical sounds for non-Arabic speakers

$$
\text { إعداد }
$$

زمرة بهلولي

\section{Zahra Bahlouli}

جامعة تلمسان - كلية الآداب واللّغات ، قسم اللغة والأدب العربي- الجز ائر

Doi: 10.21608/jnal.2021.184535

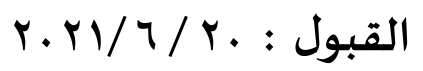

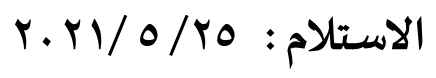

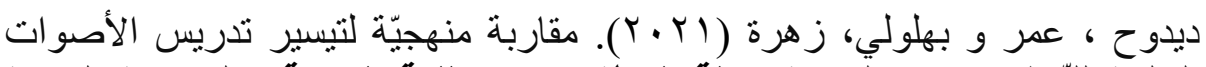

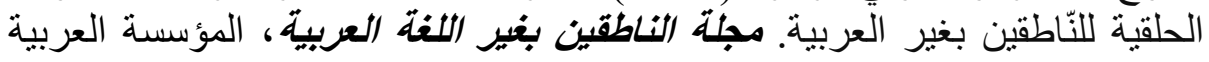

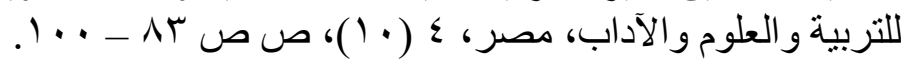




\section{مقاربة منهجيّة لتيسير تدريس الأصوات الحلقية للنّاطقين بغير العربية}

لقد بيّنت الدّراسات اللّغوية المعاصرة أنّ تعليم اللّغة العربية للنّاطقين بغيرها

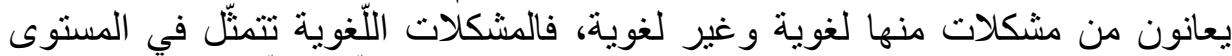

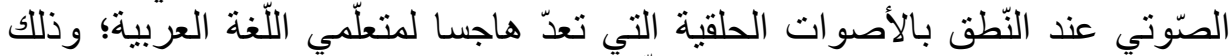

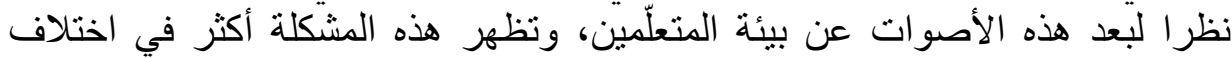

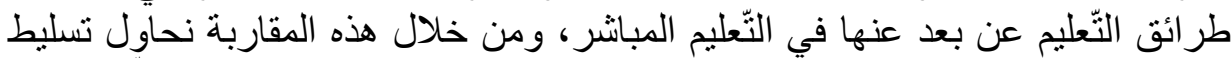

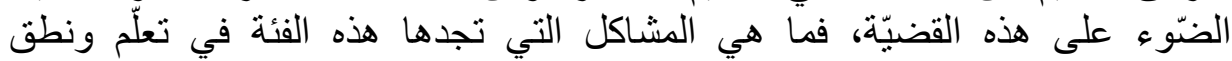

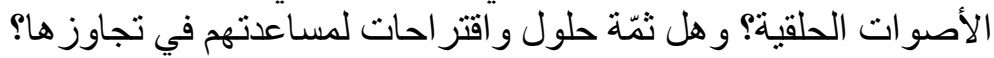
الكلمات المفتاحية: الصّوتيات، النّاطقين بغير العربية، الحلقية.

\section{Abstract:}

Contemporary linguistic studies have shown that teaching Arabic to non-Arabic speakers suffer from linguistic and nonlinguistic problems. The linguistic problems are the phonemic level when pronouncing the guttural letters, which is an obsession for Arabic language learners. This is due to the remoteness of these letters or sounds from the environment of the learners, and this problem appears more in the different methods of distance education than in direct education, and through this study we try to shed light on this issue, what are the problems that this group finds in learning and pronouncing the ring letters? Are there solutions and suggestions to help them overcome them?

Key words: phonemic, non-Arabic, speakers, letter; sounds. 
تعدّ اللّغة العربية من أغزر اللّات مادّة وأطوعها في تأليف الجمل وصياغة

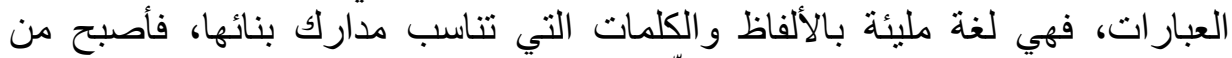

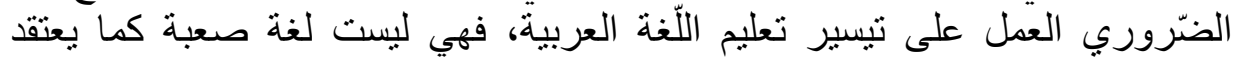

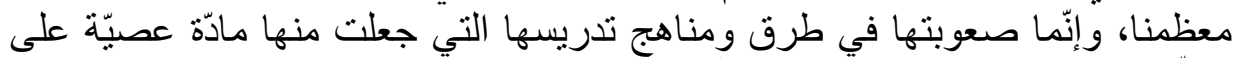

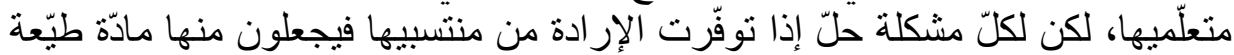

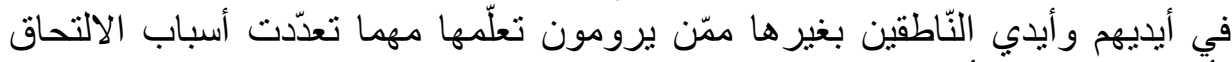
بأقسامها واختئلف وائت أعمار هم وبيئاتهم.

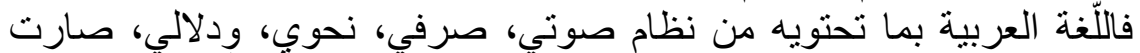

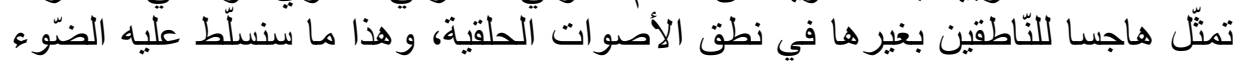

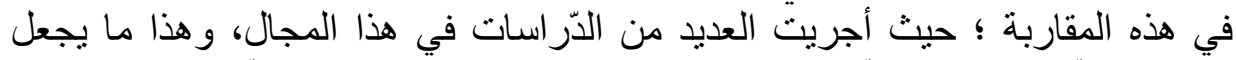

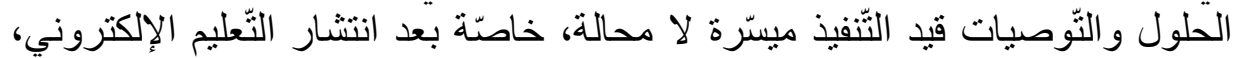

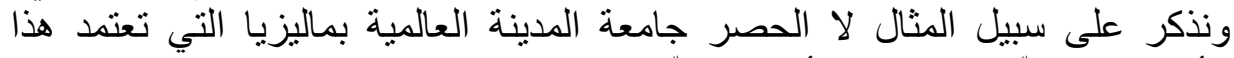

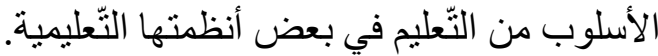

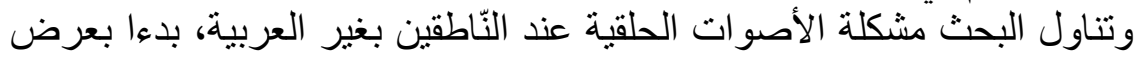

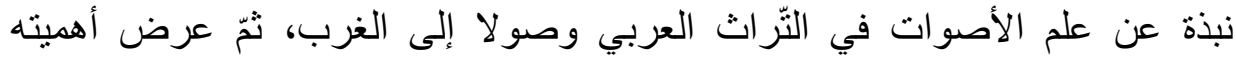

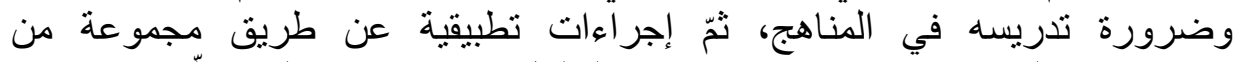

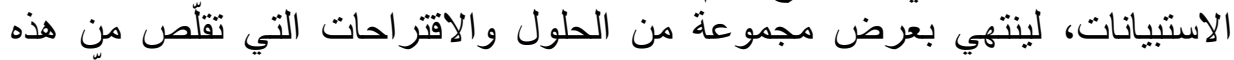

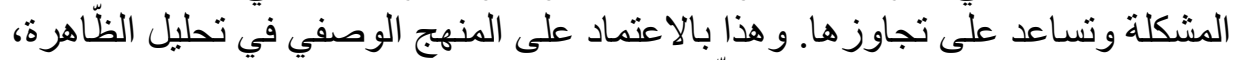

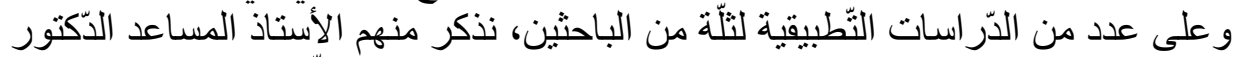

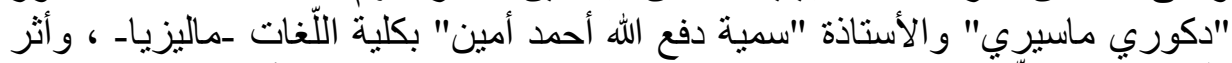

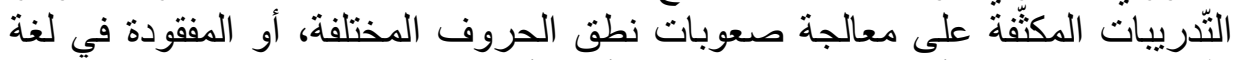

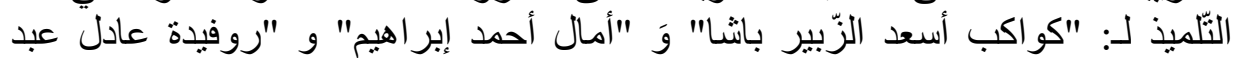

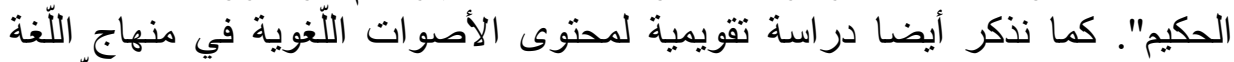

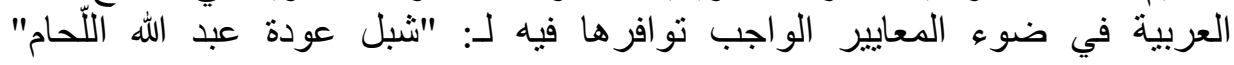
...... أعير ها.

انحصر دور العلماء القدامى في وصف جهاز النّطق عندهم في بيان مخارج

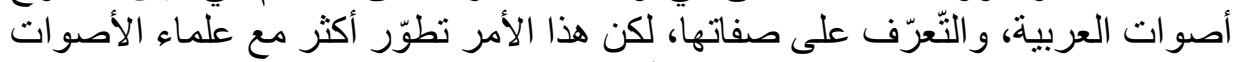

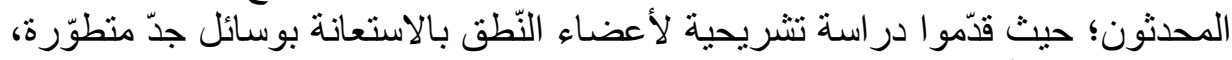

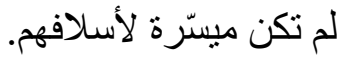




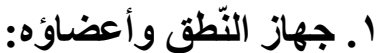

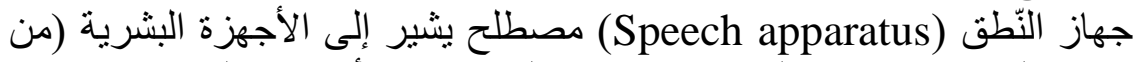
الأعضاء في الجسم الإنساني) التي تساهم في عملية تكوين الأصوات الكئ الكلاميّةّ، وجهاز

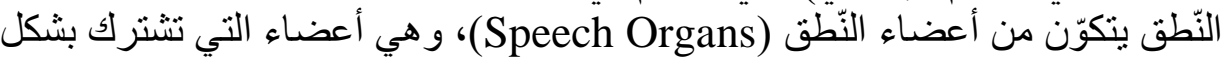
مباثر في عملية إصدار الأصوات الكلاميّة.

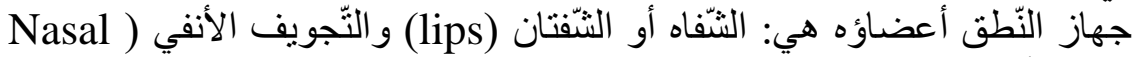

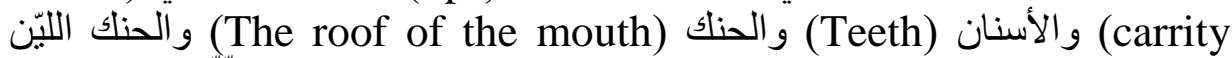

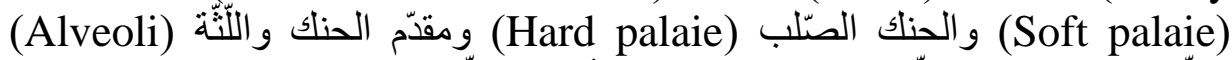

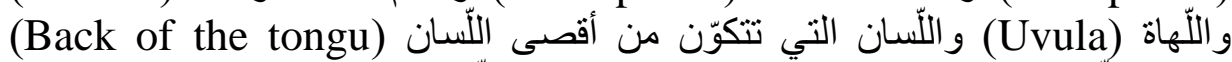

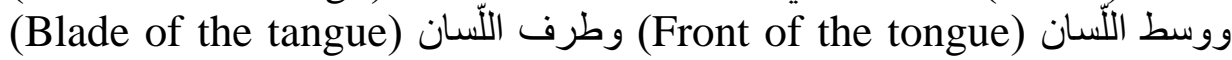

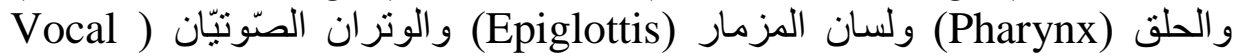

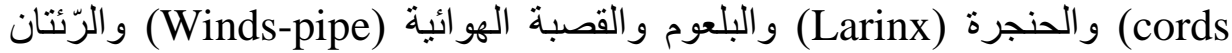
(Langs)

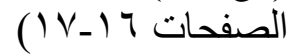

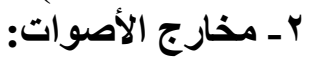

يحصر "ابن جنّي" مخارج الحروف في ستّة عشر مخرجاً، ناظراً إلى موقعها

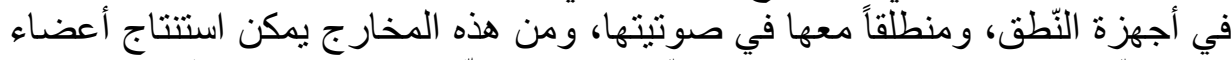

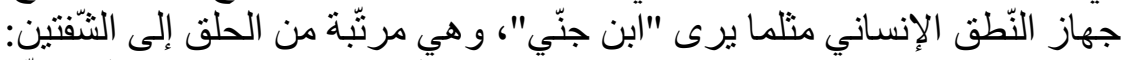

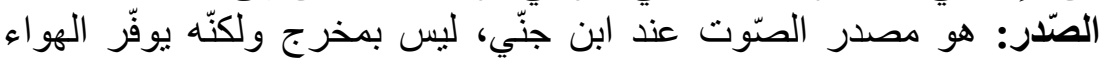
الذي بفضله يحدث تصويت.

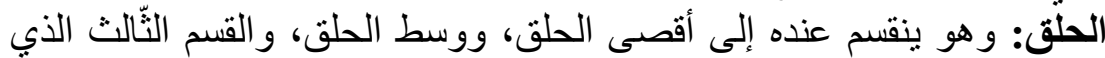

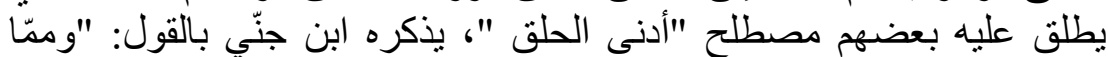

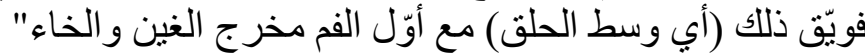
الفم: يذكر مقدّم الفهم.

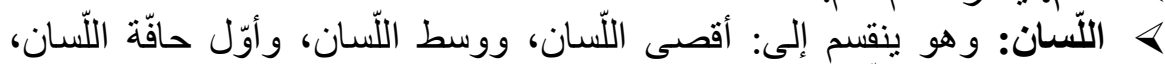

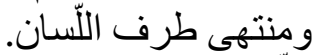
الثَّايا: وهي تضمّ: أصول الثتّايا، وأطر اف الثنّايا.

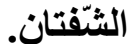

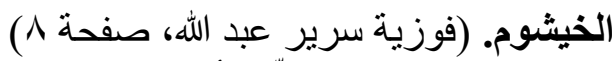

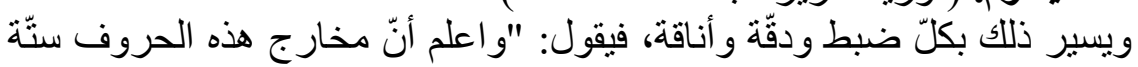

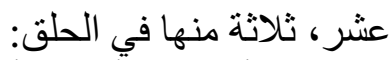
1ـ فأوَّلها من أَسفله و أقصـاه، مخرج الهمزة و الألف و الهاء. 
r - ب - ومن وسط الحلق: مخرج العين و والحاء.

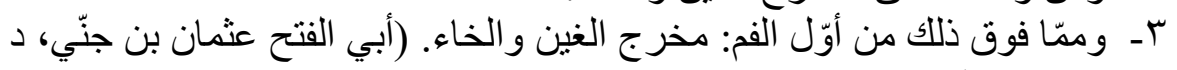

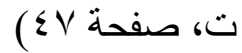

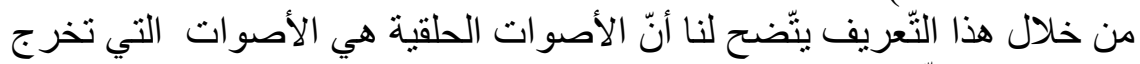

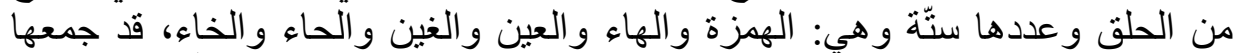

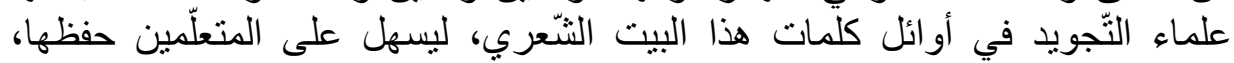

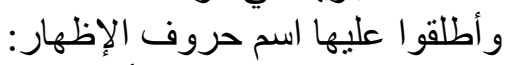
أخي هالك علما حساز هـير خـاسر.

أـ تعريف الحلق: الحلق في علم التّشريح، هو الجزء الدّاخلي من الرّقبة، أمام الفقرات العنقية.

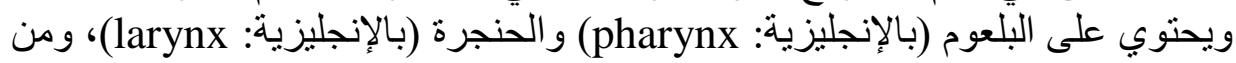

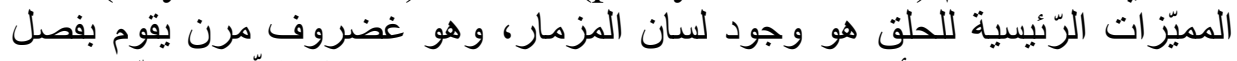

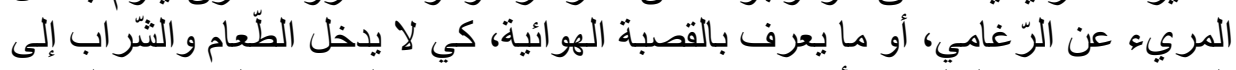

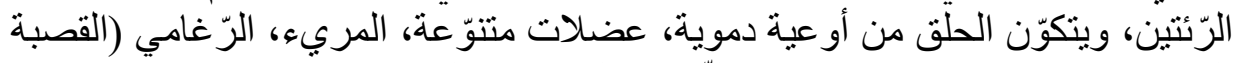

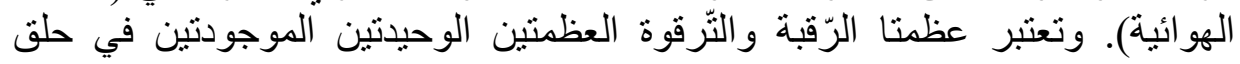
الإنسان. (https://ar.wikipedia.org) بيّنت الأبحاث الحديثة أنّ التّعرّف على صفات الأنى الأصوات عمليّة مرتبطة بجهاز

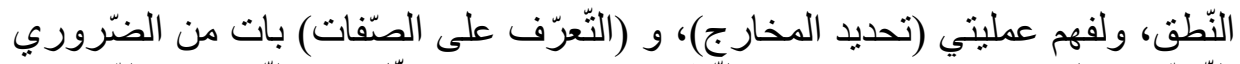

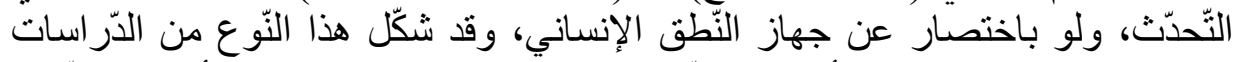

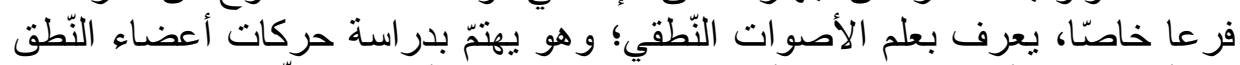

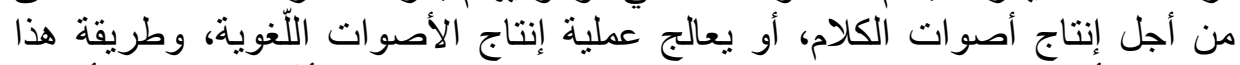

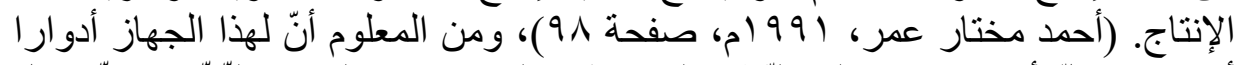

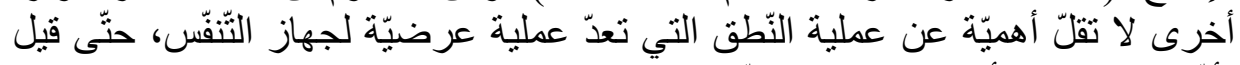

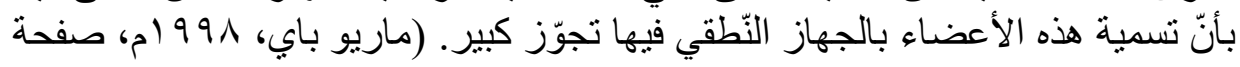
rـ النّظرية الصّوتية بين التّراث العربي والدّراسات الغربية:

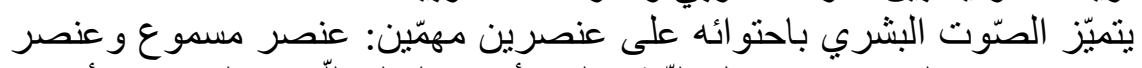

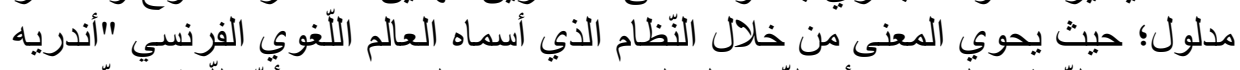

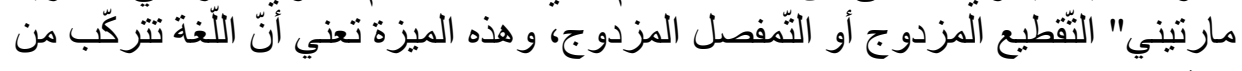
مستويين: 
> مستوى الفونيم: وهو الصّوتيات الصَّيرة الخالية من المعنى، وهي أصغر

وحدة دلالية.

> مستوى المونيم: وهو مركّب من صوتيات لتصير أصغر وحدة دلالية في

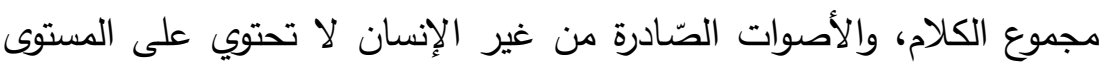

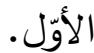

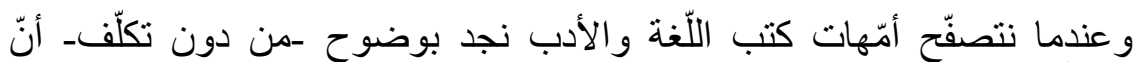

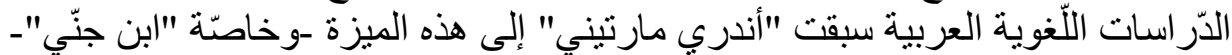

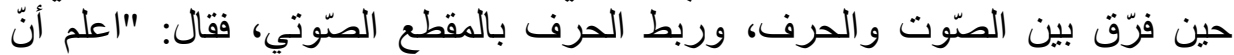

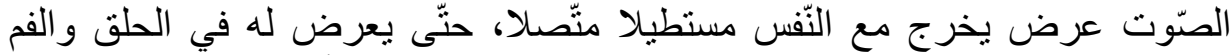

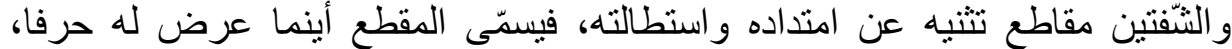

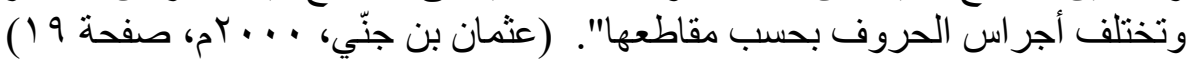

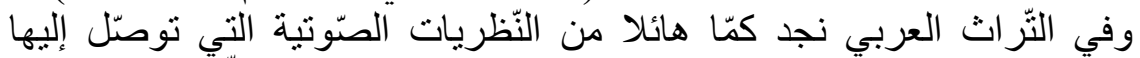

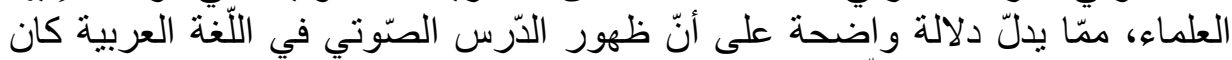

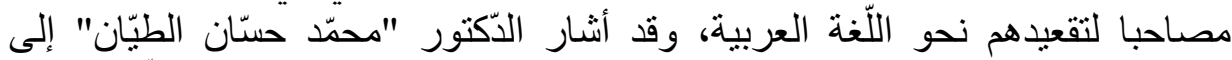

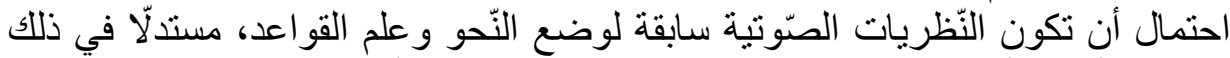

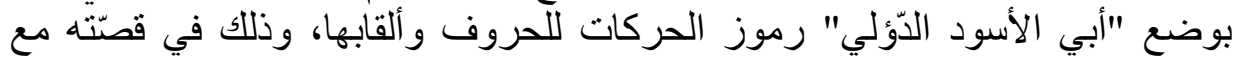

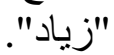

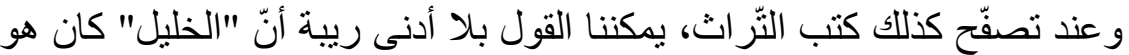

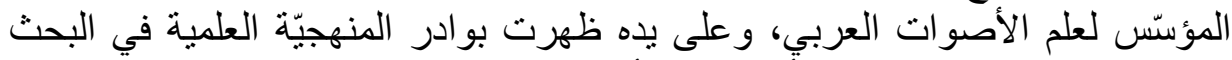

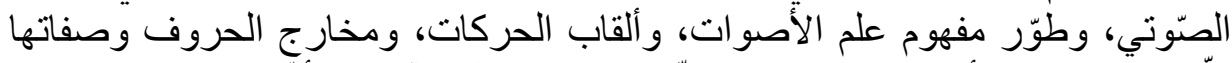

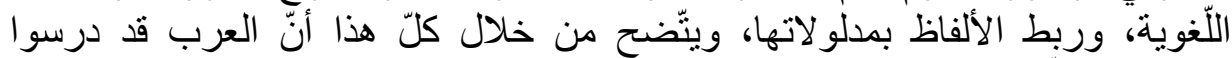

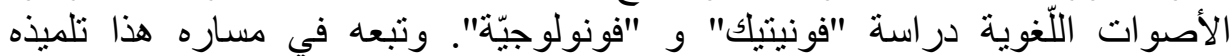

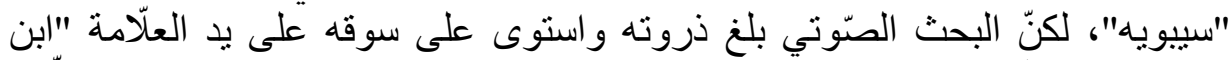

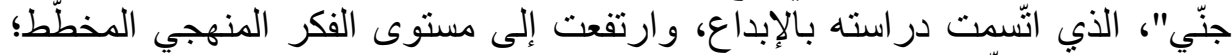

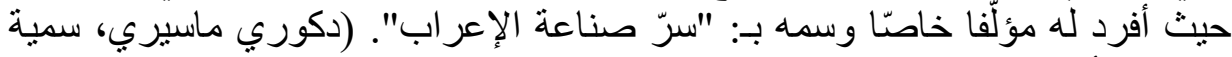

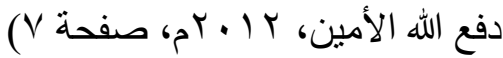

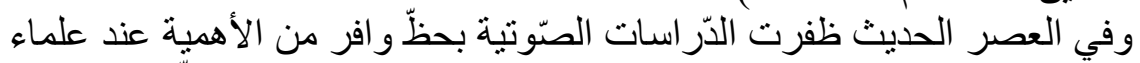

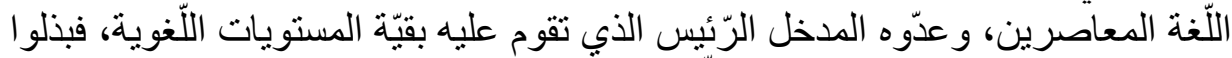

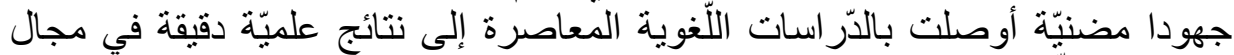

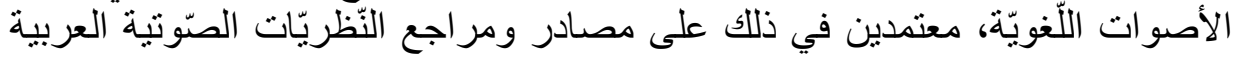




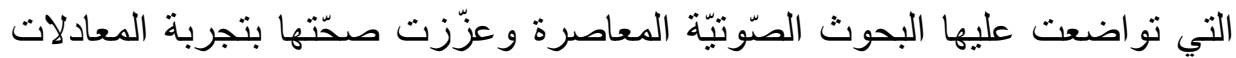

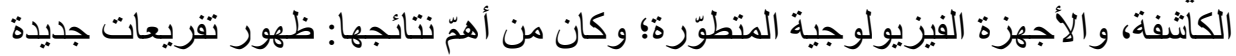

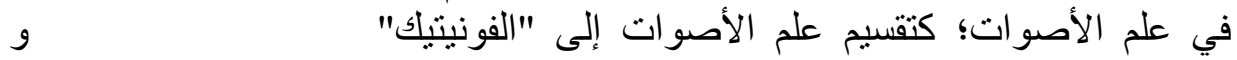

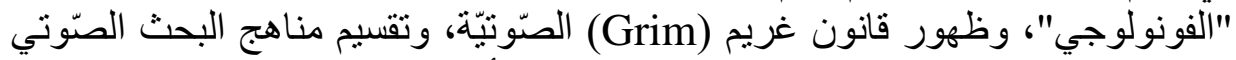

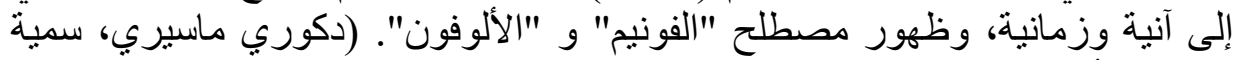

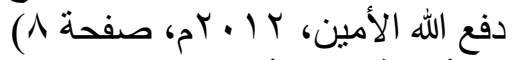

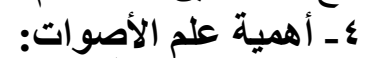

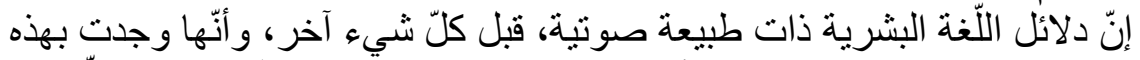

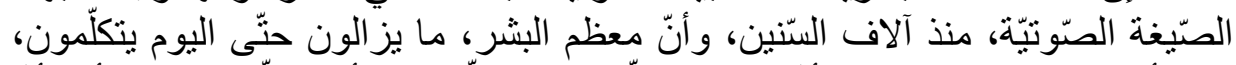

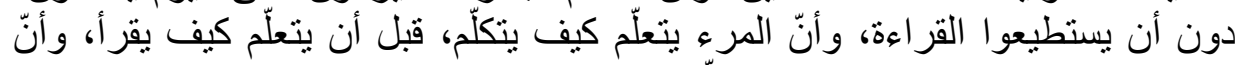

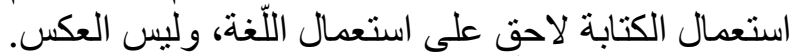

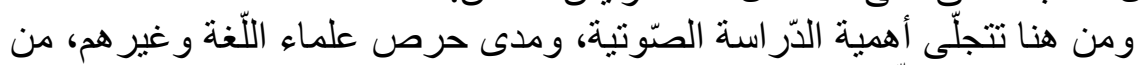

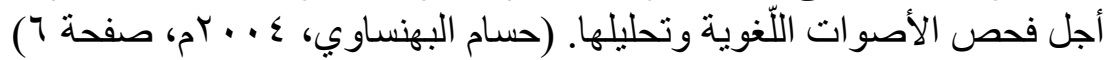

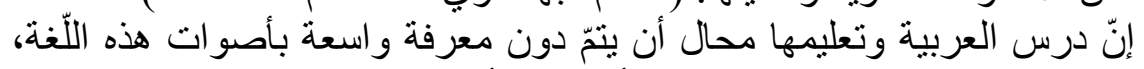

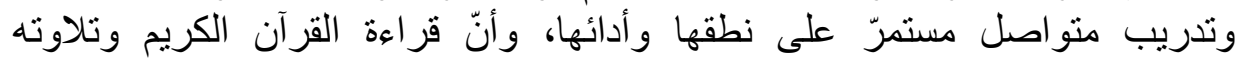

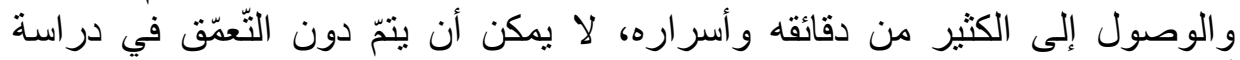

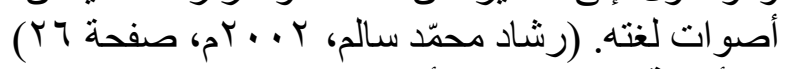

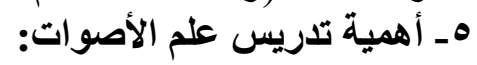

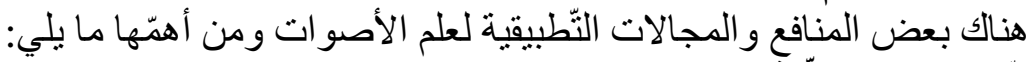

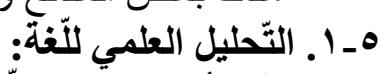

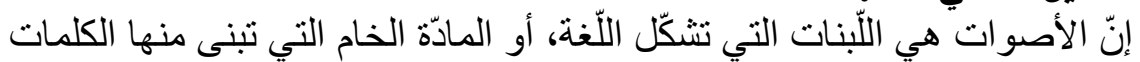

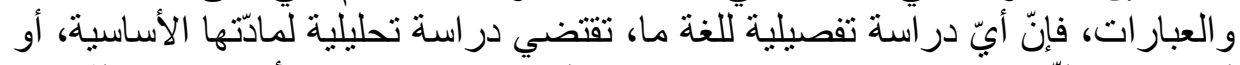

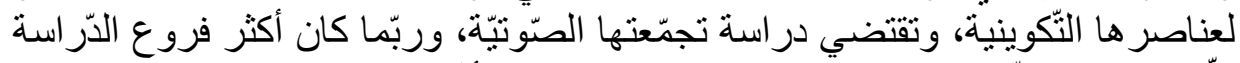

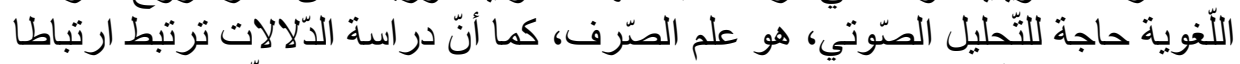

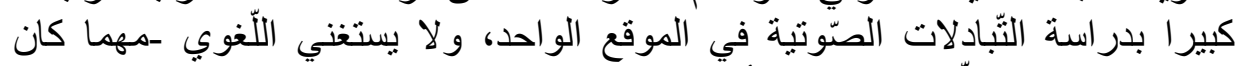

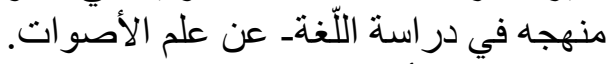

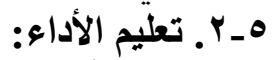

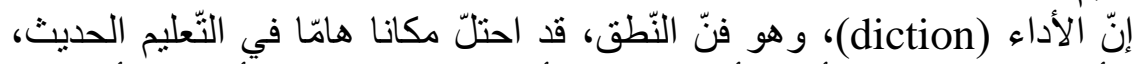

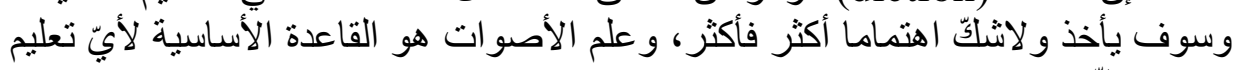
من هذا التّوع. 


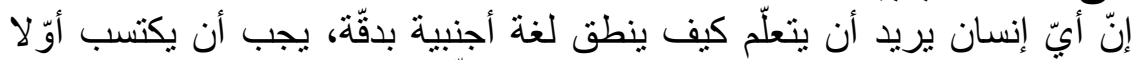

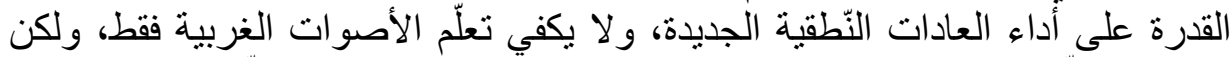

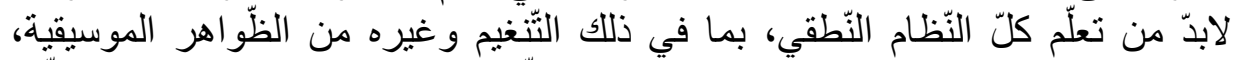

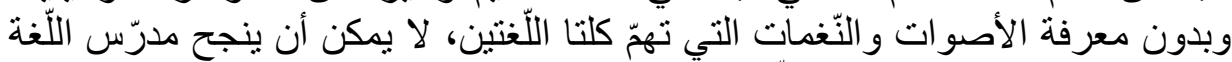
في تدريس تلاميذه النّقن الجيّد للَّة الجديدة.

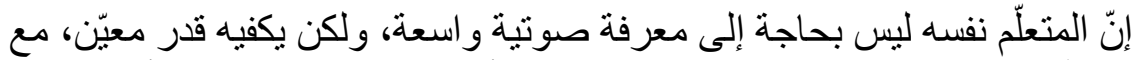

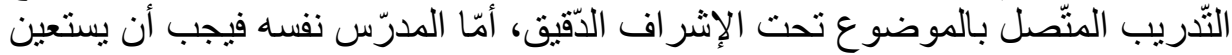

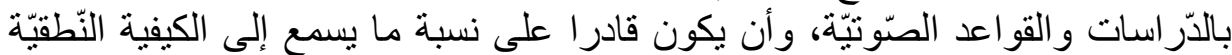

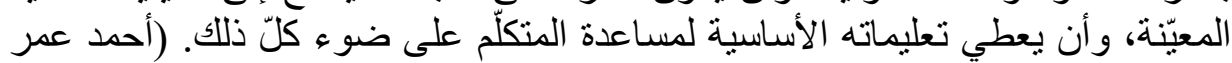

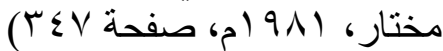

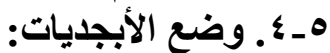

أحسن طريقة لكتابة اللّات قائمة على الصّوت، أنّاته يمكناتك أن تعطي رموزا

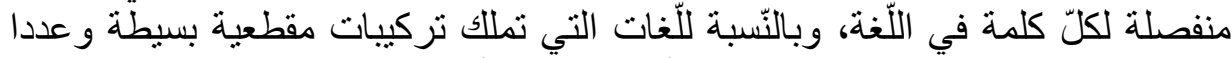

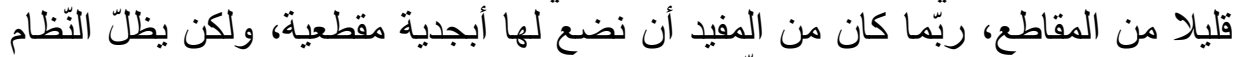

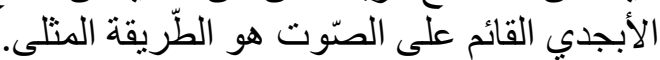

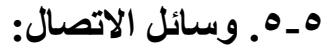

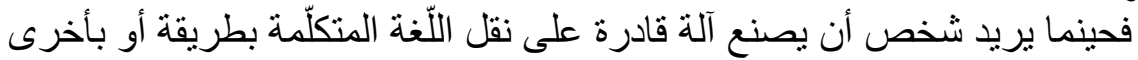

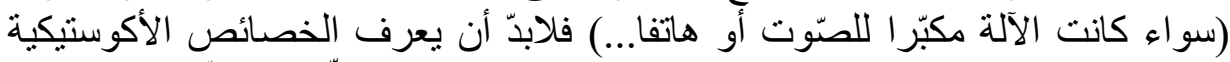

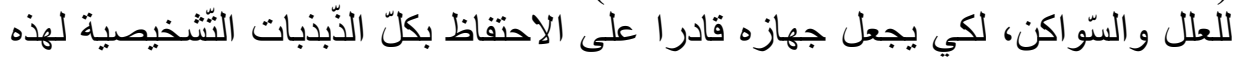

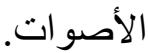
هــآ. تعليم الصمّ و علاج عيوب الستّمع والنّطق:

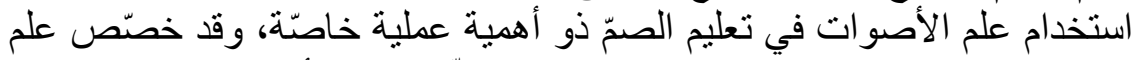

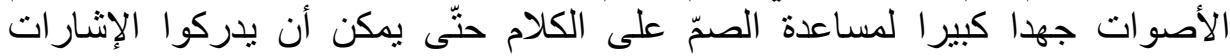

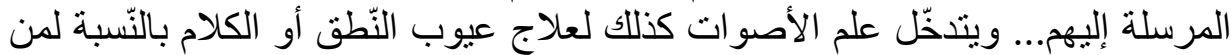

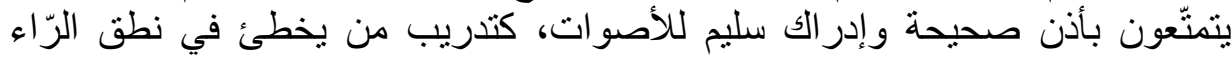

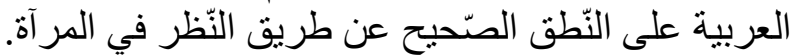

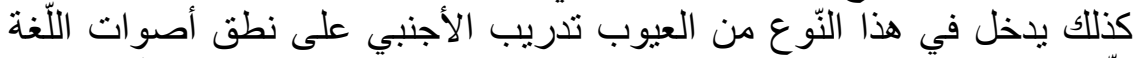

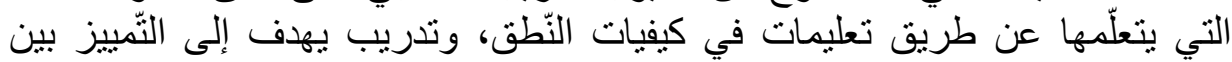

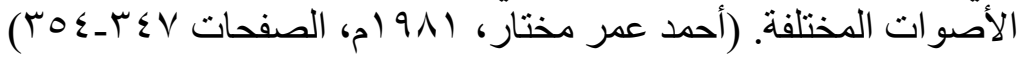




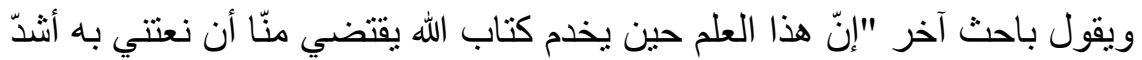

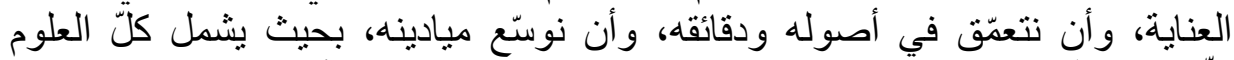

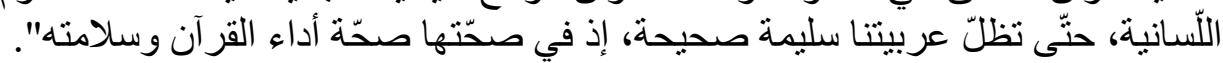

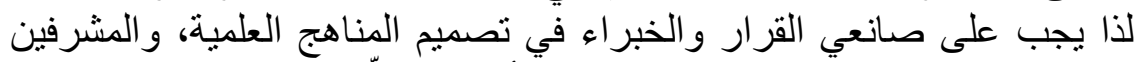

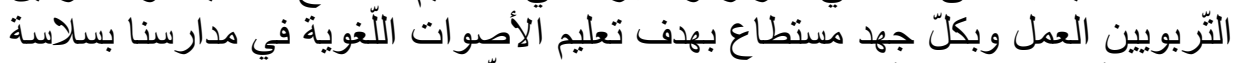

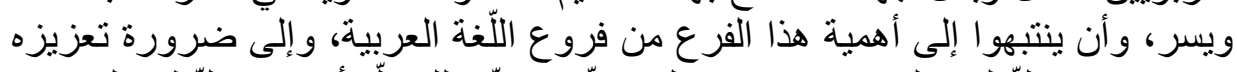

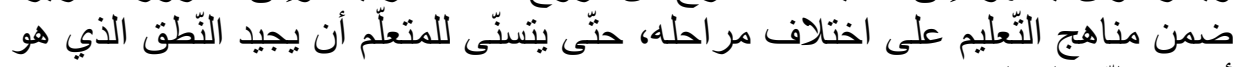

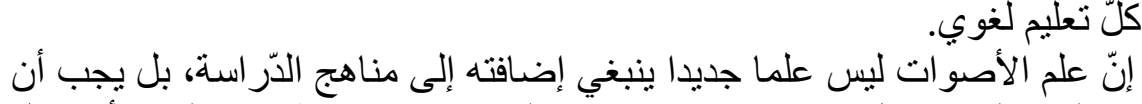

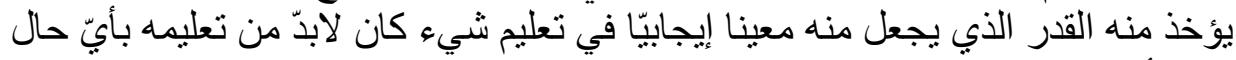

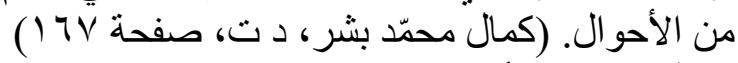

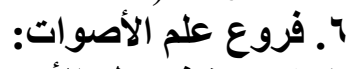
7- ا ـ تصنيف علم الأصوات الأصوات من ناحية ماديتها ووظيفتها: أـ القونيتيك:

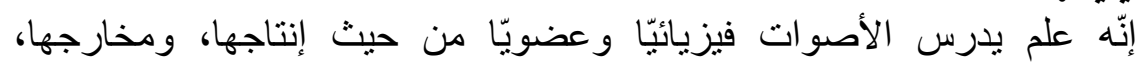

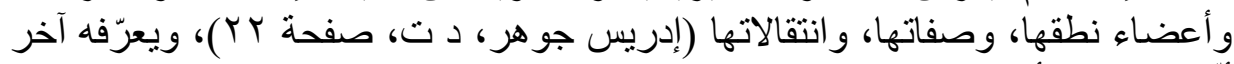

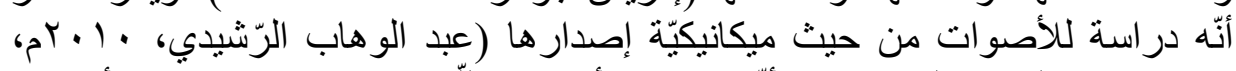

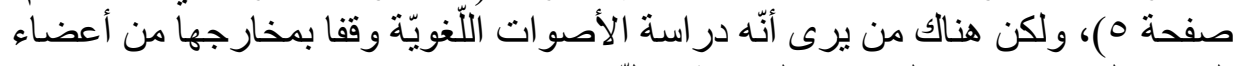

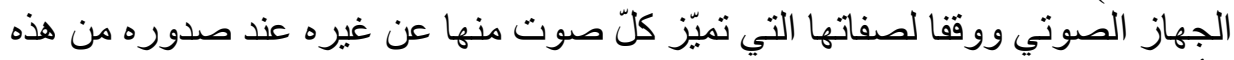

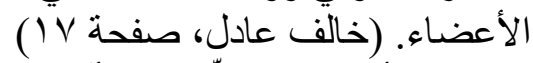
ورأى معظم اللّسانيين أنّه علم يدرس أصوات الكّات الكلام دون النّظر إلى وظائفها

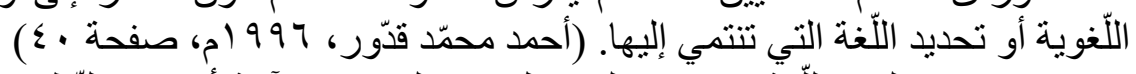

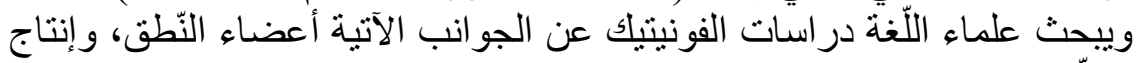

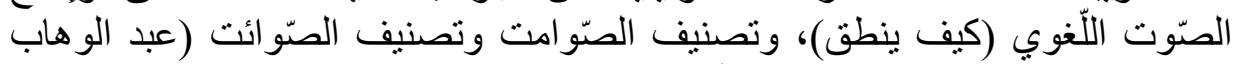

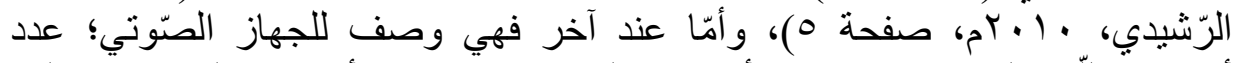

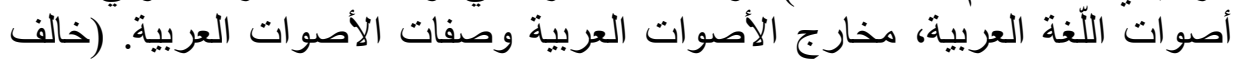

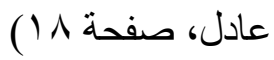

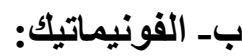

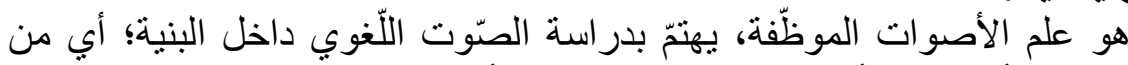

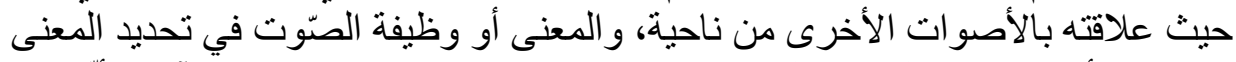

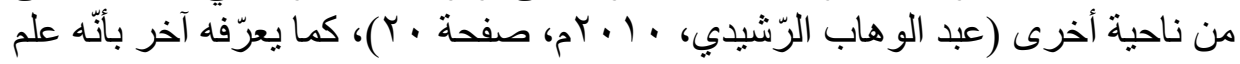


يهنتّ بالصّوتيات الوظيفية، و اقتصر لذلك على دراسة الوحدات الصّوتية فيسمّى بعلم

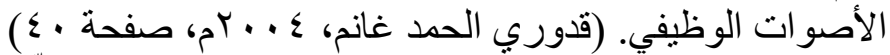

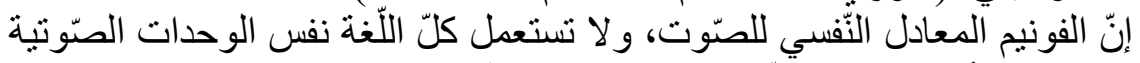

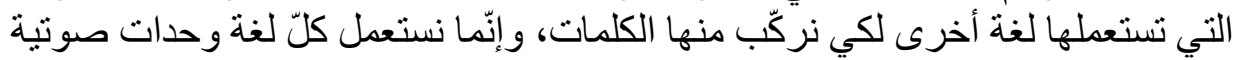

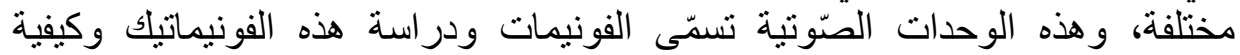

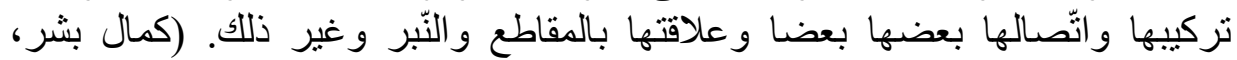

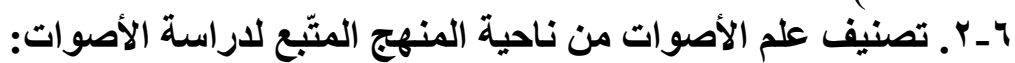

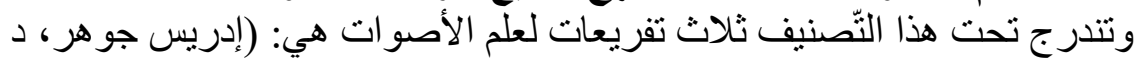

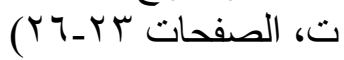

تقسيم إلى علم الأصوات الوصفي و علم الأصوات المعياري.

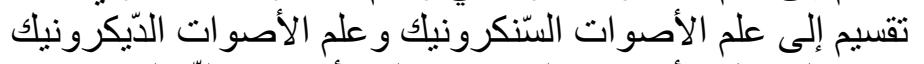

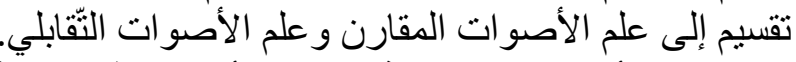
ج-r. تصنيف علم الأصوات من ناحية ميسرة الأصوات في عملية الكلام:

$$
\begin{aligned}
& \text { علم الأصو ات النّطقي. } \\
& \text { علم الأصوات الأكوستكيو. }
\end{aligned}
$$

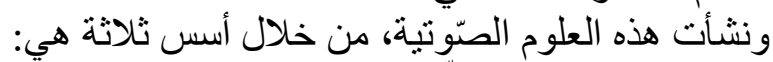

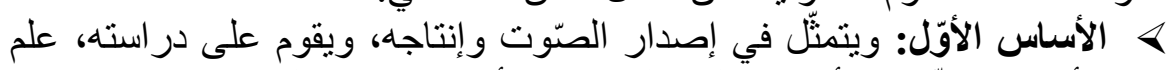

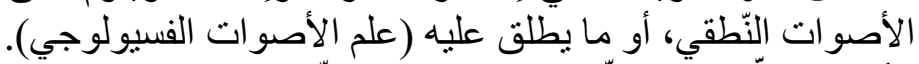

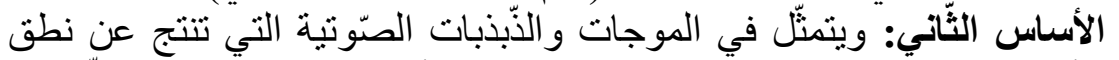

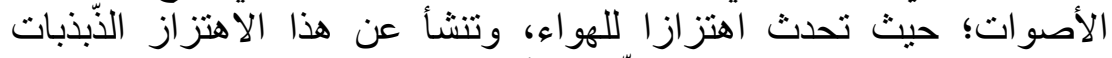

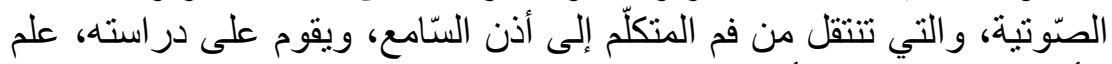
الأصوات الفيزيائي الأكوستيكي).

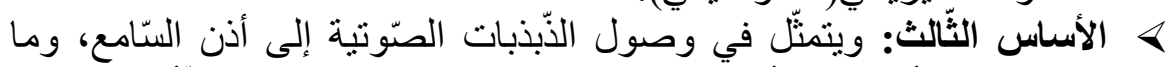

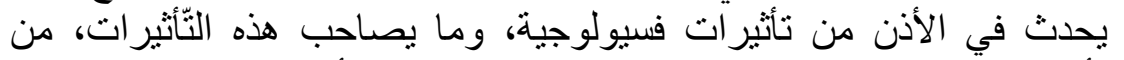

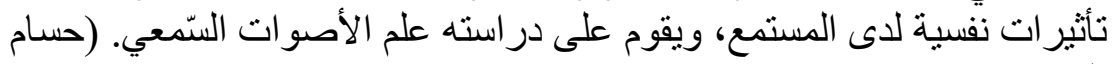

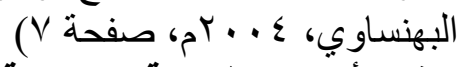

ז- أ. وصف الأصوات العربية من ناحية مخارجها:

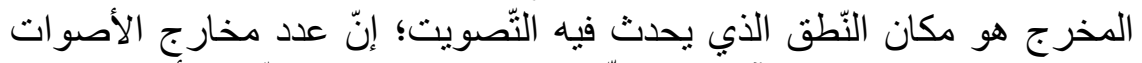

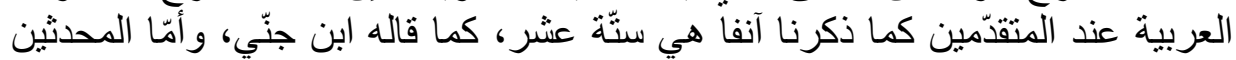

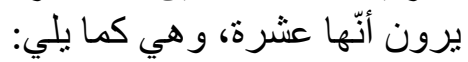




$$
\begin{array}{r}
< \\
< \\
<
\end{array}<
$$

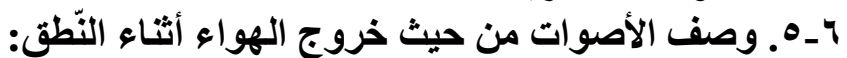

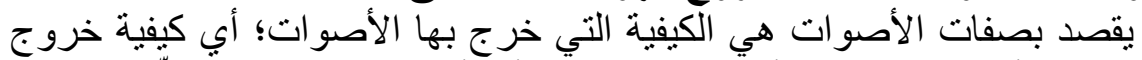

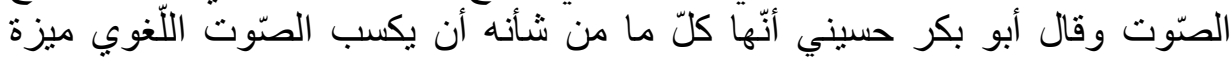

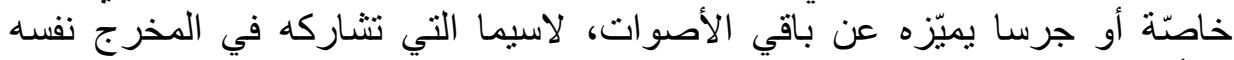

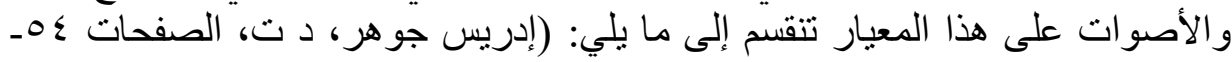
ه الأصوات الانفجارية: وتسمّى أيضا بأصوات شديدة أو أصوات وقفية وهي ثمانية

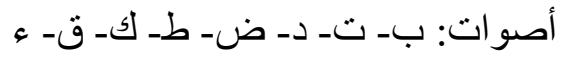

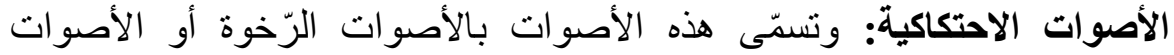

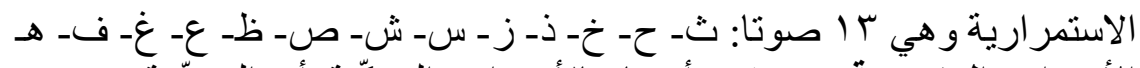

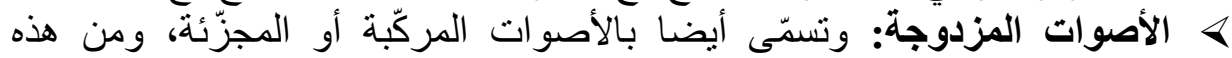

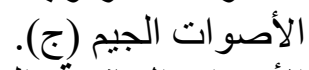

\& الأصوات الجانبية: الصّّوت الجانبي الوحيد في اللّّة العربية هو اللّام (ل).

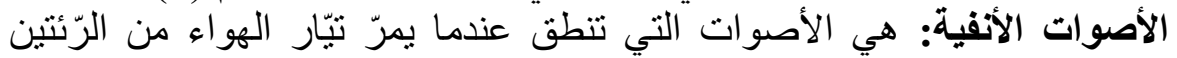

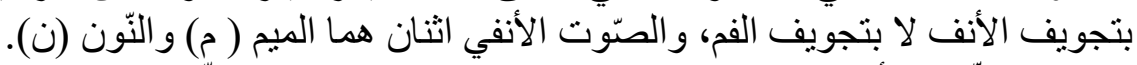

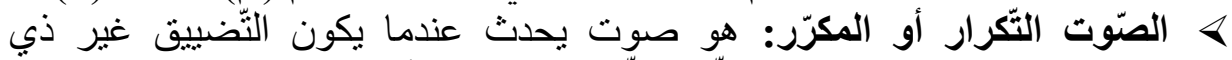

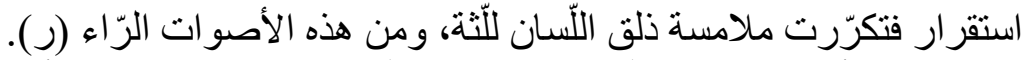

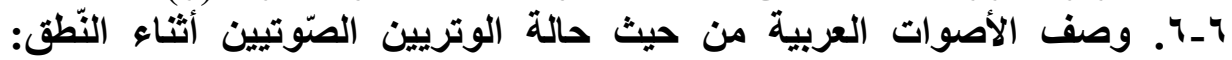

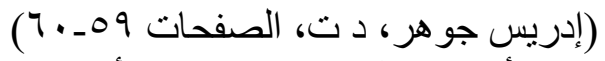

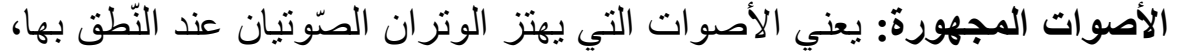

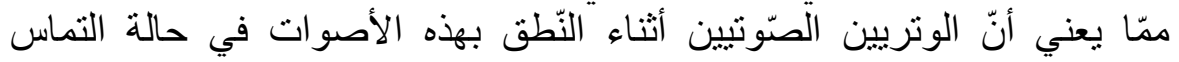

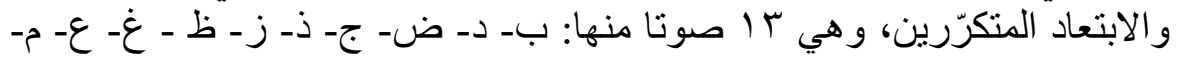


ن- ل- ر. وتضاف إلى هذه الأصوات (الصّامتة) جميع الأصوات الصنّائتة أو

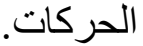

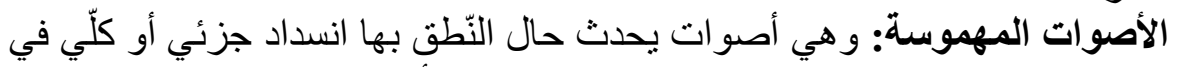

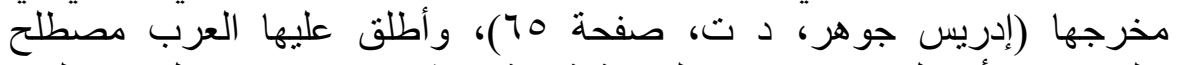

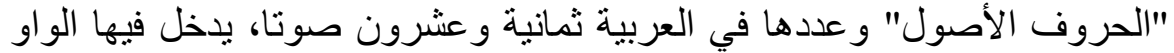

و الياء غير المديتين. (Eva Latifah Fauzia, 2019, p. 52)

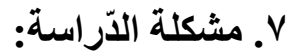

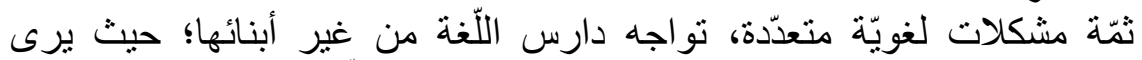

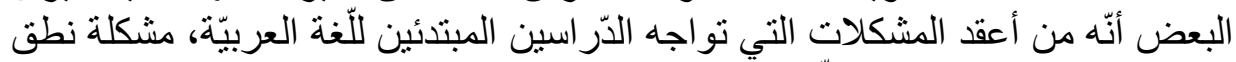

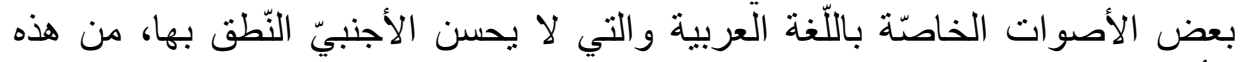

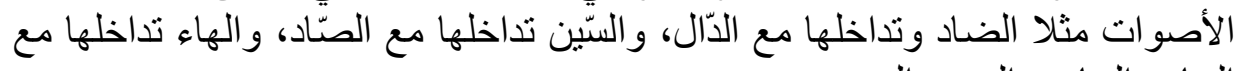

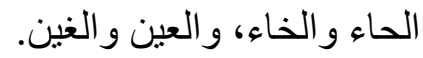

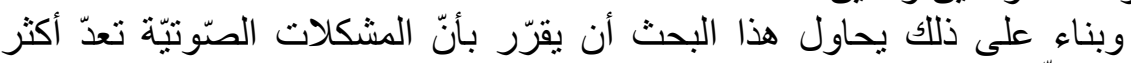

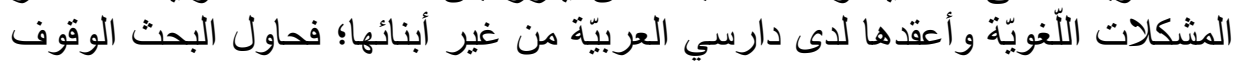

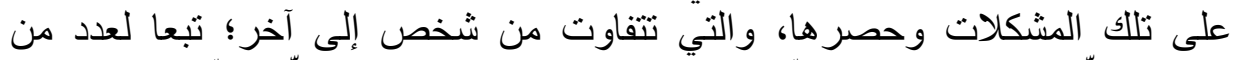

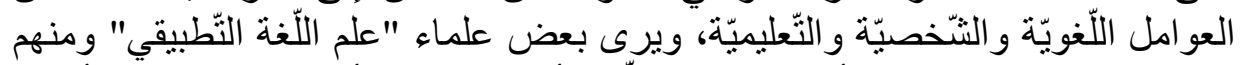

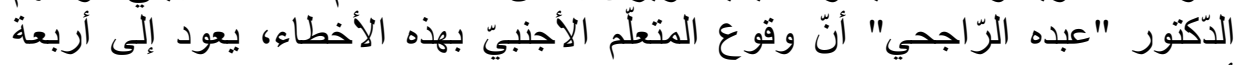

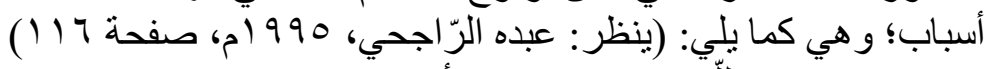

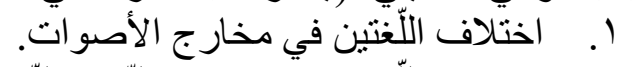

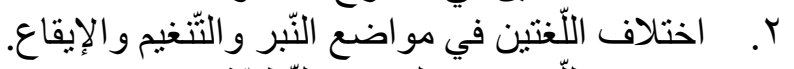

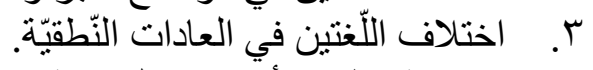

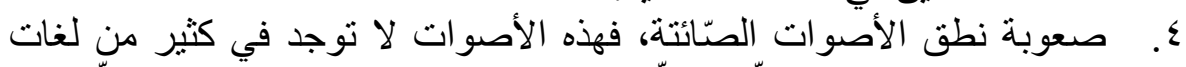

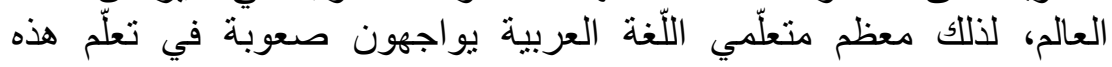

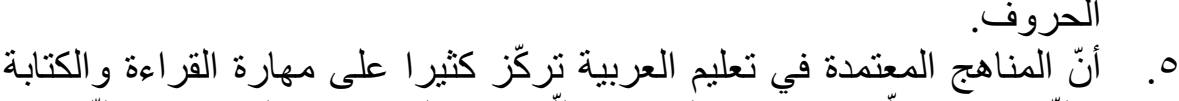

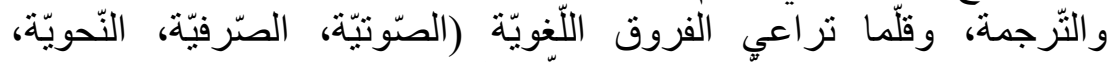
والدّلاليّة) الموجودة في اللّغة العربية واللّغة القومية.

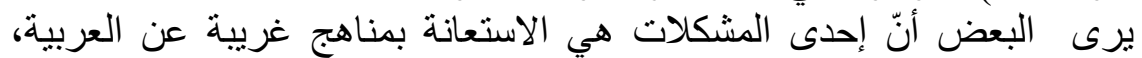

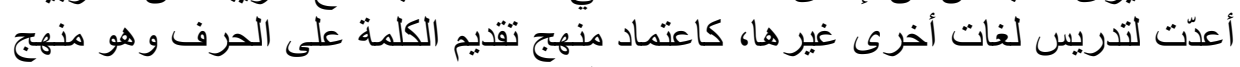

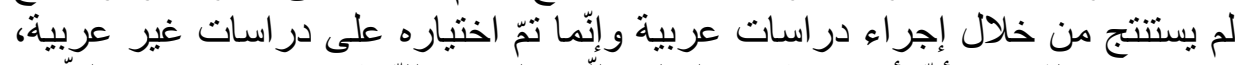

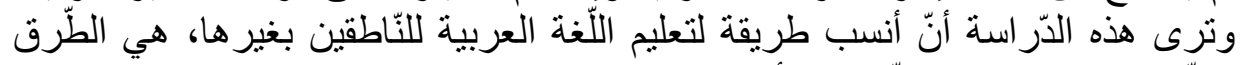

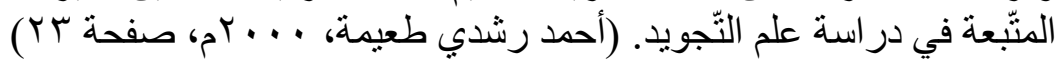




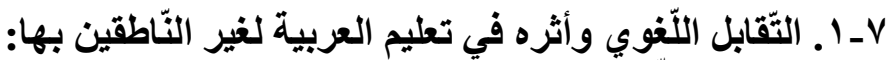

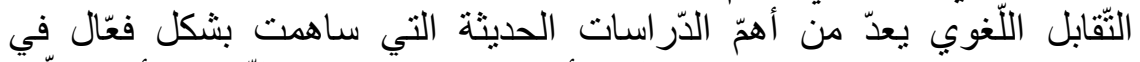

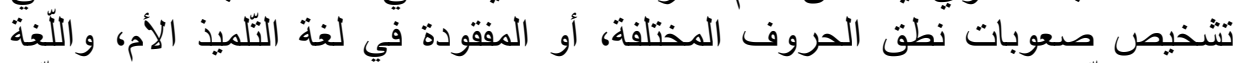

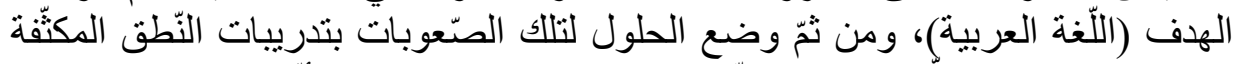

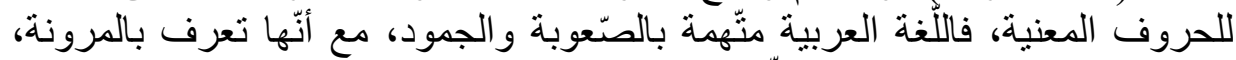

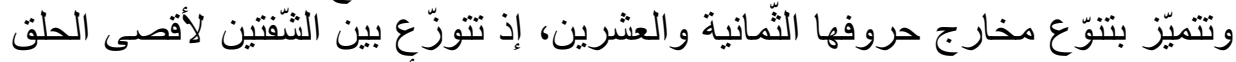

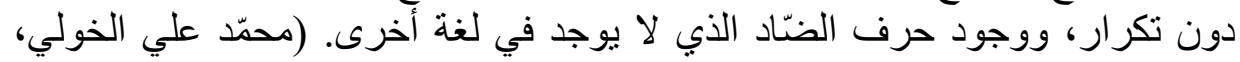

(9T)

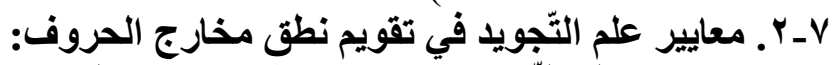

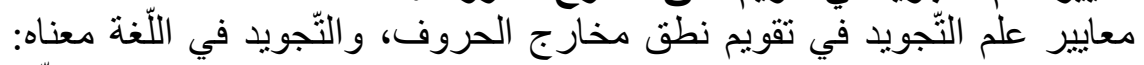

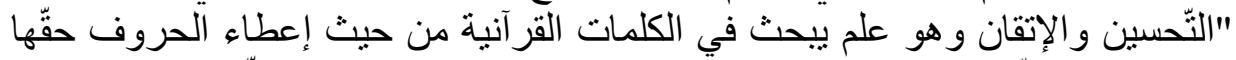

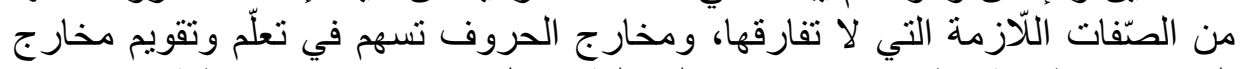

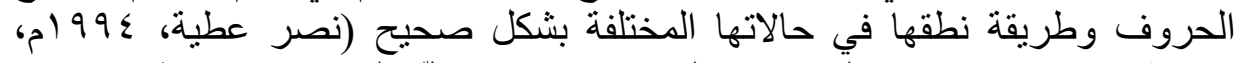

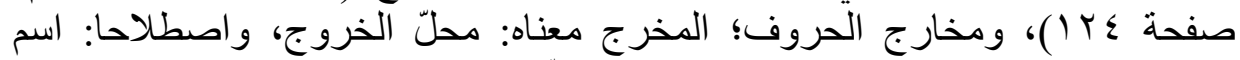

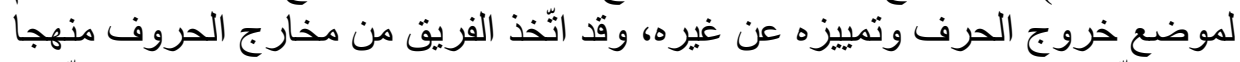

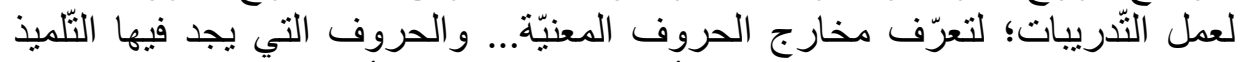

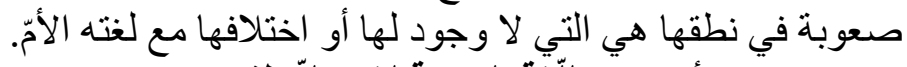
V-r-v

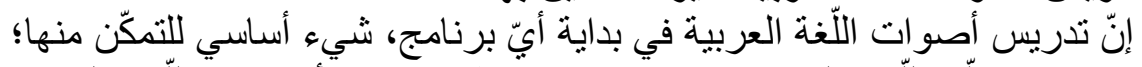

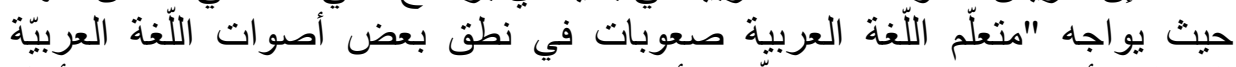

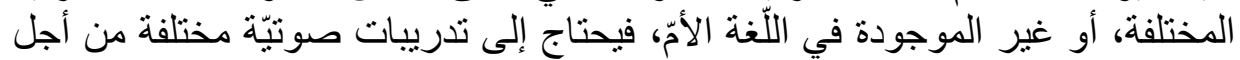

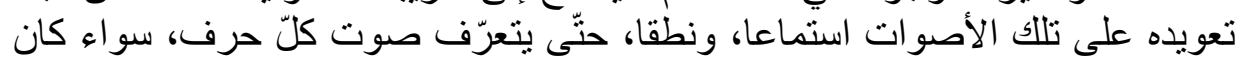

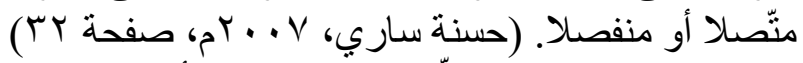

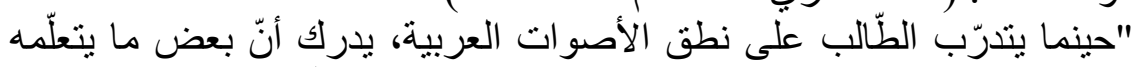

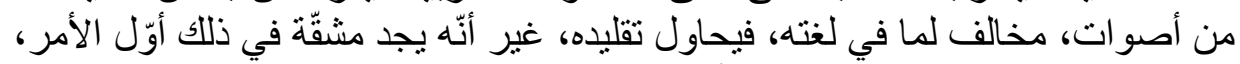

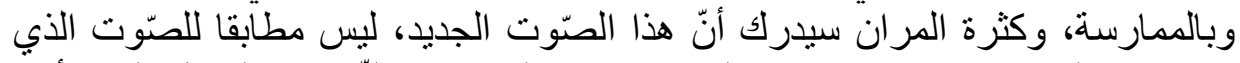

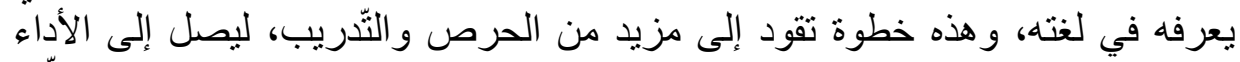

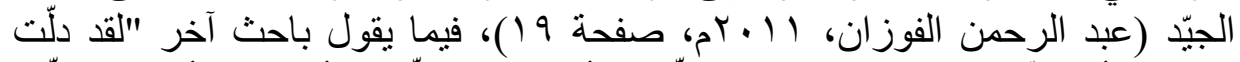

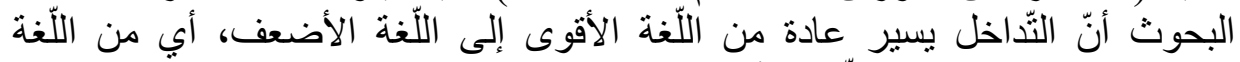

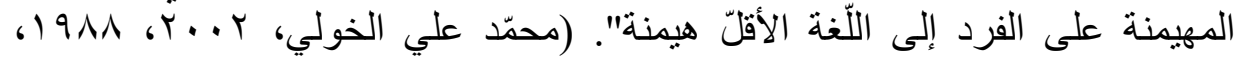

صفحة 70) V-ـ أ. الصّعوبات التي تواجه النّاطقين بغير العربية في نطق الأصوات الحلقية: 
قامت العديد من الدّراسات ببحث مشكلة نطق الأصوات الحلقية لادى المتعلّمين

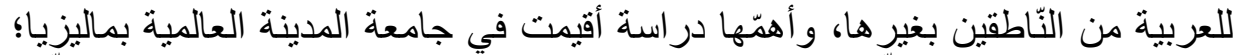

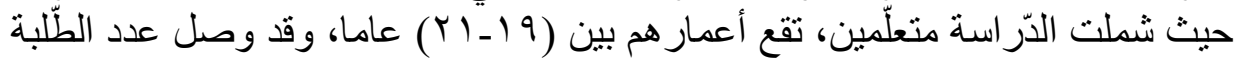

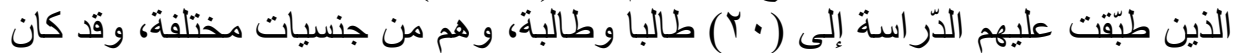

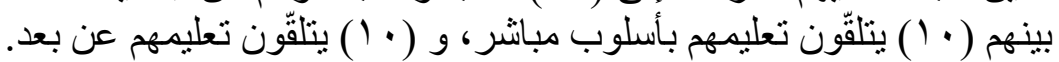

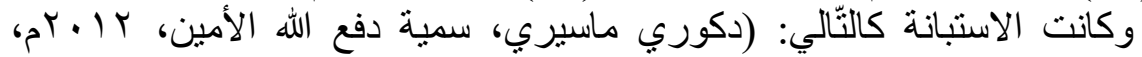

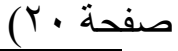

\begin{tabular}{|c|c|c|c|}
\hline$\gamma$ & نعم & المعاييز & \\
\hline$r$ & IV & هل تجد صعوبة في نطق الصّوتين الحلقيّين (العين & 1 \\
\hline 0 & 10 & 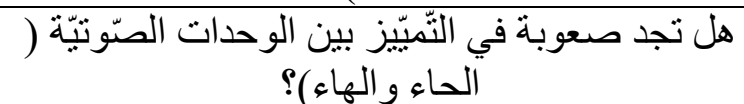 & $r$ \\
\hline 7 & $1 \leq$ & هل تجد صعوبة في نطق الأصوات الطَّقيّة ( الخاء & $r$ \\
\hline$\mu$ & iv & هل تجد صعوبة في نطق الأصوات الحنجريّة ( الهاء & $\varepsilon$ \\
\hline$\varepsilon$ & 17 & هل تعاني من نطق الأصو ات وقد وردت في كلمات؟ & 0 \\
\hline r & IV & هل لديك طرق للتّّلب على المشكلات التي تتعرّض & 7 \\
\hline
\end{tabular}

شكل رقم 1 يوضّح نسبة كلّ الصّعوبات الموجودة في الاستبانة نطق الأصو ات الحلقية

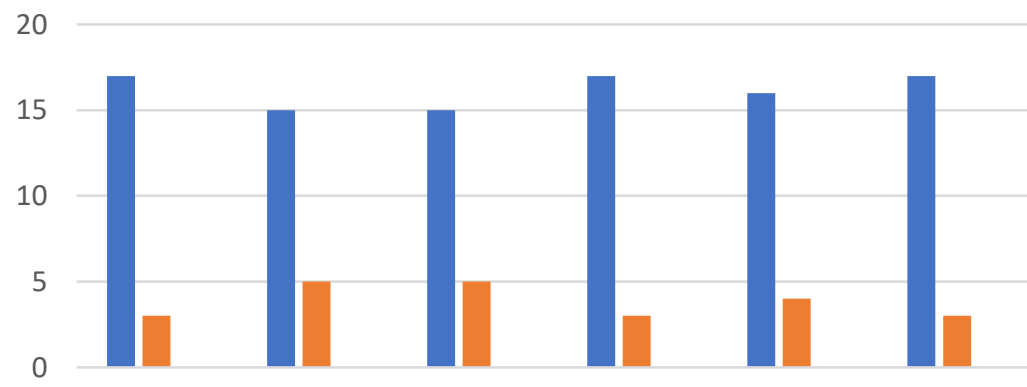

Catégorie 1 Catégorie 2 Catégorie 3 Catégorie 4 catégorie5 categorie6 घérie 1 - Série 2 - Série 3 


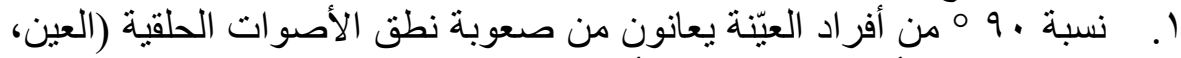

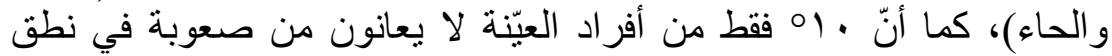

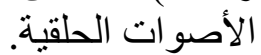
Y. نسبة .مهمن أفراد العيّنة يعانون من نطق الأصوات الحنجرية (الهاء

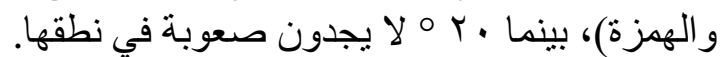

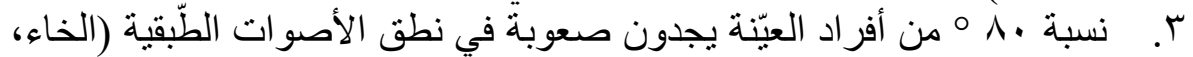

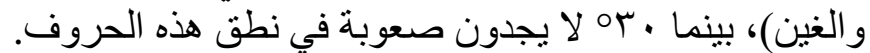

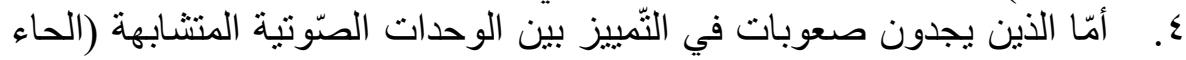

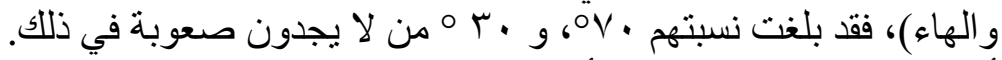

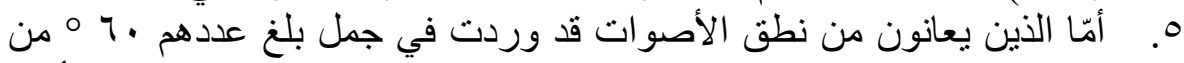

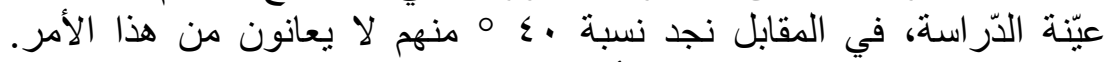

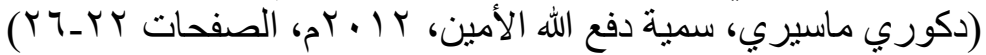

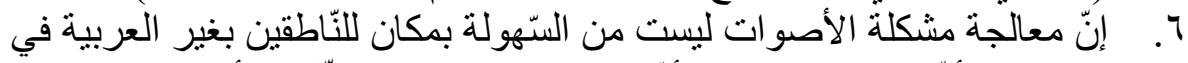

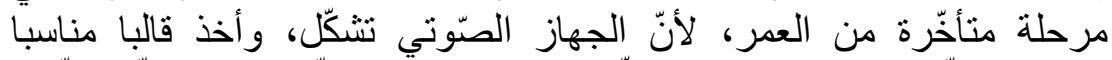

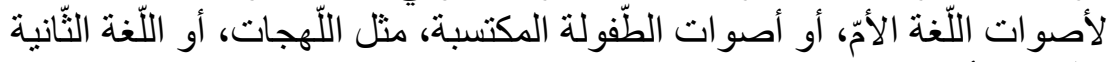
الثقبيهه بالأمّ.

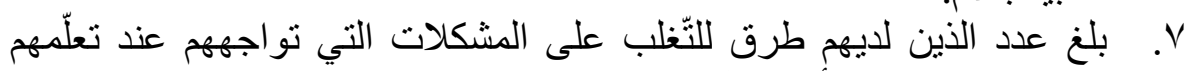

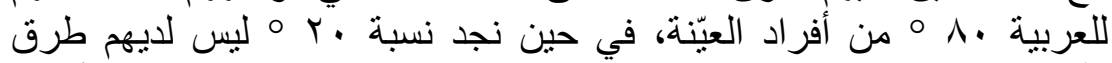

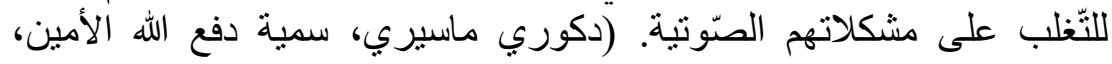
(ro (T)

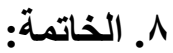

من خلال هذا البحث ظهر لنا أنّ المشكلات الصَّوتية لدى النّاطقين بغير العربية

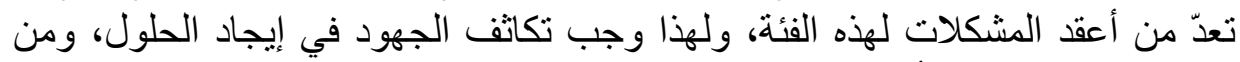

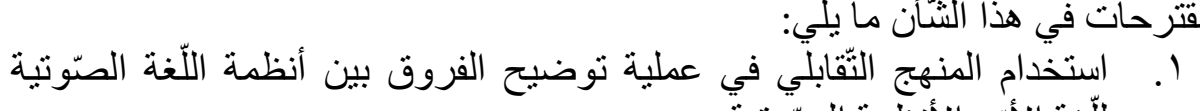

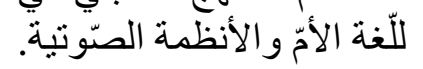

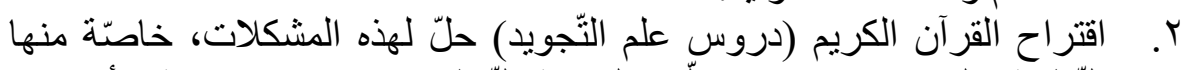

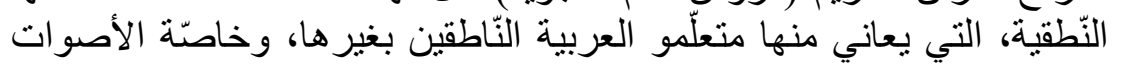
الحلقية. 
r. وجود برنامج حاسوبي واستغلاله في التّقيم الصّوتي للعربية: ينطق متعلّم

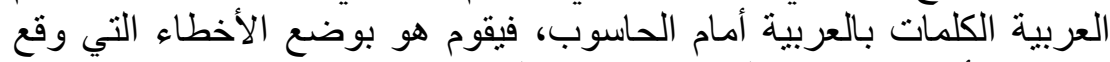

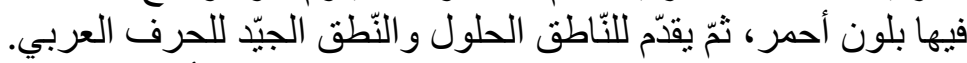

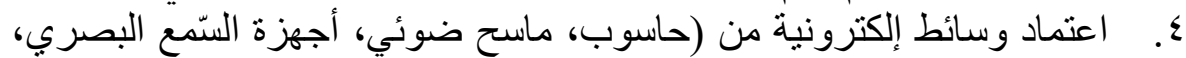
الثنّاثة الإلكترونية).

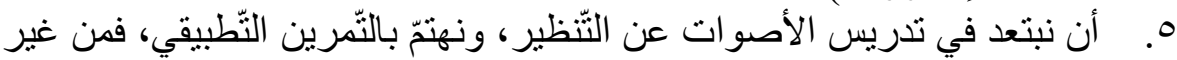

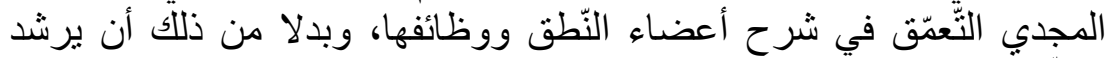

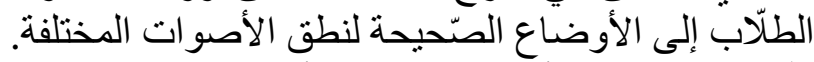

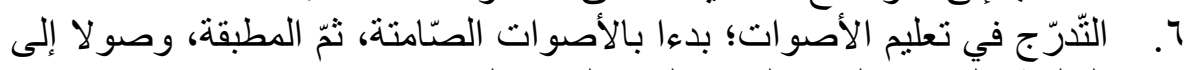

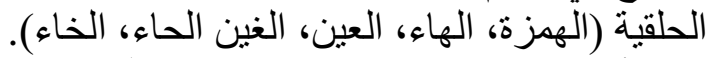

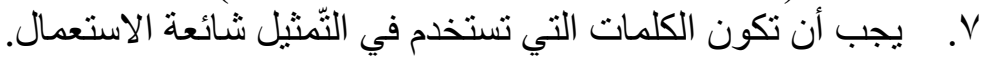

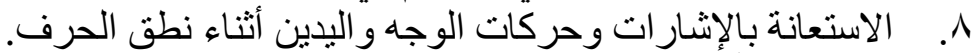

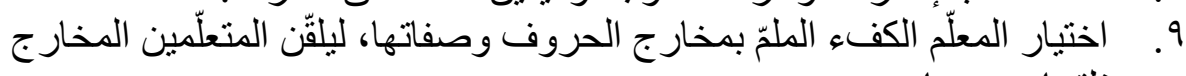

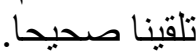


ا. أبي الفتح عثمان بن جنّي. (د ت). سرّ صناعة الإعراب، ، تحقيق: حسن

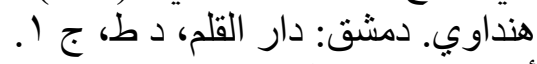

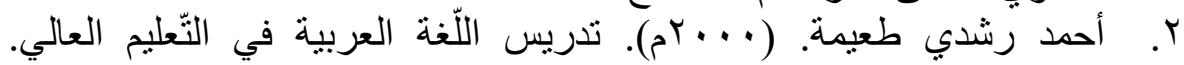

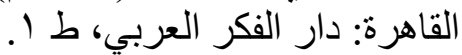

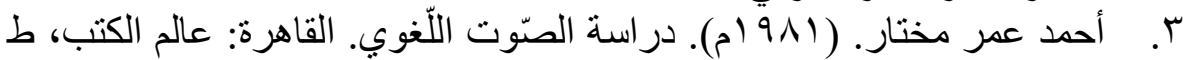

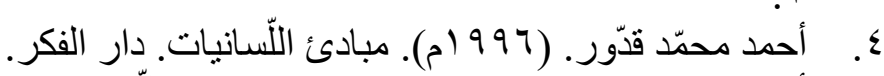

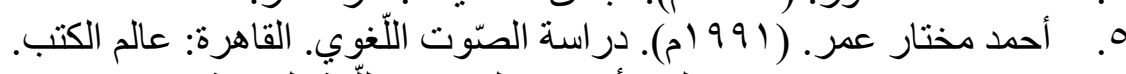

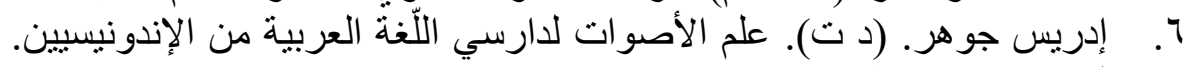
لسان عربي، د ده.

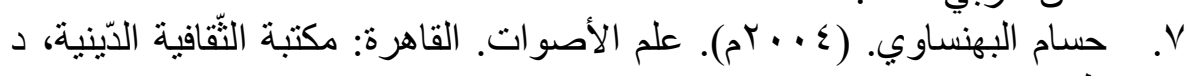
ط.

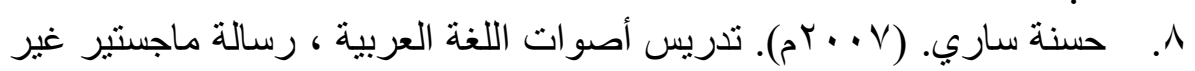
منشورة. جامعة الامام بنجول الإن الإسلامية، إندونيسيا.

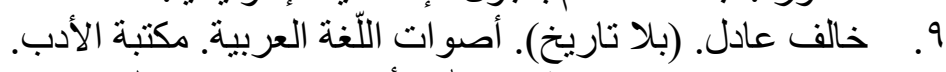

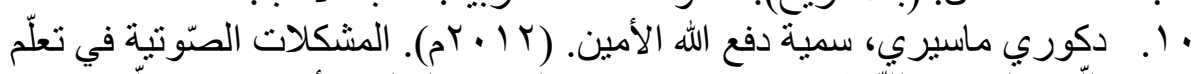

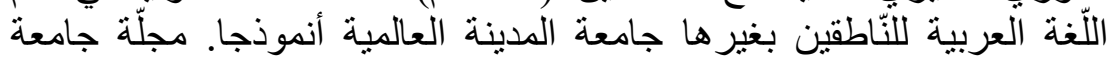
المدينة العالمية(0).

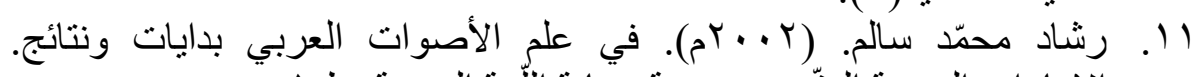

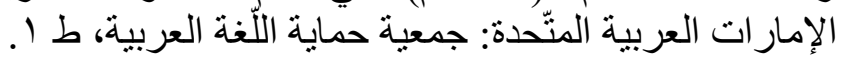

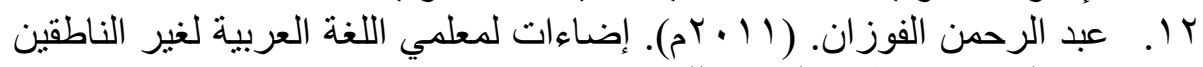

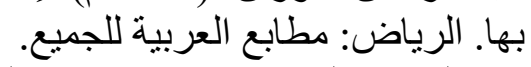

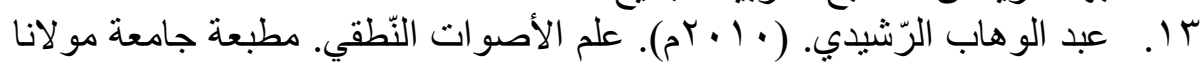

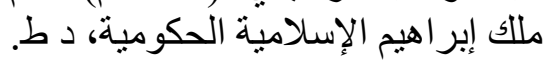

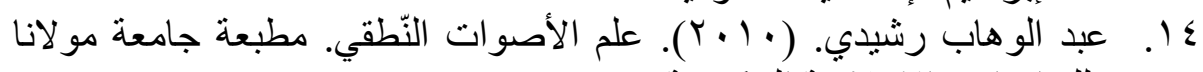

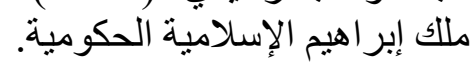

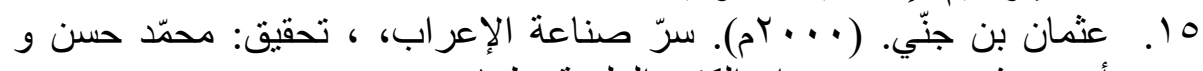

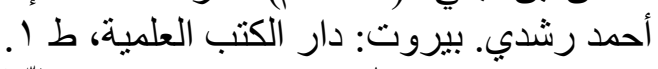
17

$$
\text { و المحدثين- ابن جنّي و لندرسي. مجلّة الصّّوتيات (1 ( ) ). }
$$




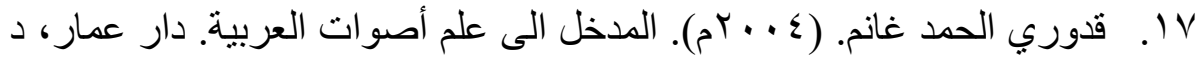
ط. 1 1. . كمال بشر. (بلا تاريخ). علم الأصوات. دار غريب، د ط.

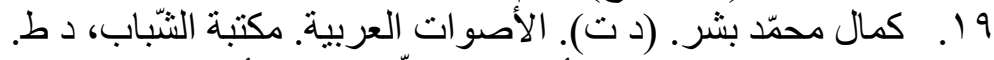

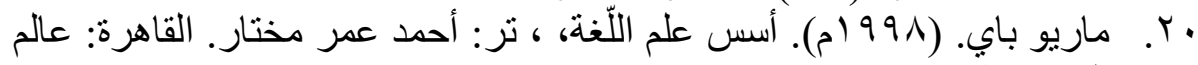
الكتب، ط ماريو باي.

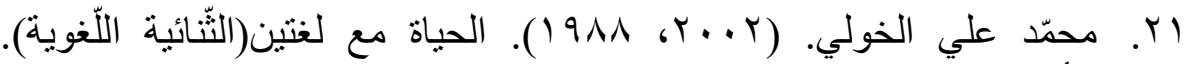

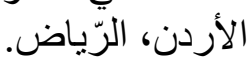

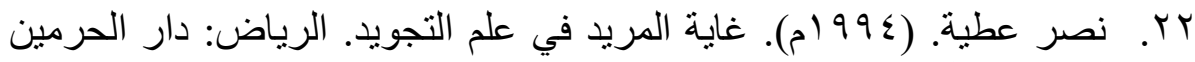

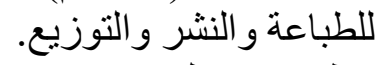

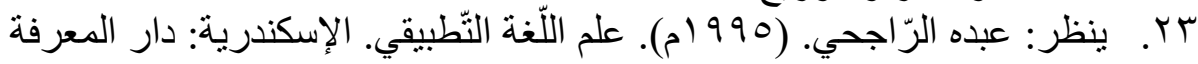

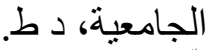

1. (s.d.). Récupéré sur https://ar.wikipedia.org.

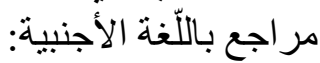

2. Abdallah, ي. A. (2005). language centrc. London .

3. Eva Latifah Fauzia. (2019). اختلافات دراسة علم الأصوات بين العربية و اللسانيات الحديثة. Journal of arabic and english language. 